\title{
Agile in the Era of Digitalization : A Finnish Survey Study
}

\section{Kettunen, Petri}

Springer Nature Switzerland

2019

Kettunen , P , Laanti , M , Fagerholm , F \& Mikkonen, T 2019, Agile in the Era of Digitalization : A Finnish Survey Study . in X Franch , T Männistö \& S Martínez-Fernández (eds), Product-Focused Software Process Improvement : 20th International Conference, pÿPROFES 2019, Barcelona, Spain, November 27 29, 2019, Proceedings . Lecture Notes in Computer Science, vol. 11915 , Springer Nature Switzerland, Cham , pp. 383-398, International Conference on Product-Focused Software Process Improvement, Barcelona , Spain , 27/11/2019.https://doi.org/10.1007/978-3-030-35333-9_28

http://hdl.handle.net/10138/321620

https://doi.org/10.1007/978-3-030-35333-9_28

unspecified

acceptedVersion

Downloaded from Helda, University of Helsinki institutional repository.

This is an electronic reprint of the original article.

This reprint may differ from the original in pagination and typographic detail.

Please cite the original version. 


\title{
Agile in the Era of Digitalization: A Finnish Survey Study
}

\author{
Petri Kettunen ${ }^{10000-0002-2928-5885]}$, Maarit Laanti ${ }^{2}$, Fabian Fagerholm ${ }^{1,3[0000-0002-7298-3021]}$ \\ and Tommi Mikkonen ${ }^{10000-0002-8540-9918]}$ \\ ${ }^{1}$ University of Helsinki, Department of Computer Science, Finland \\ \{petri.kettunen, fabian.fagerholm, tommi.mikkonen\}@helsinki.fi \\ ${ }^{2}$ Nitor Delta, Helsinki, Finland \\ maarit.laantienitor.com \\ ${ }^{3}$ Blekinge University of Technology, Sweden \\ fabian.fagerholm@bth. se
}

\begin{abstract}
Agile software development has been applied since the early 2000s. It is now mainstream industrial practice in information and communication technology (ICT) companies and IT organizations. However, recently increasing and even disruptive digitalization has brought new drivers and needs for agility both in software organizations as well as in traditional companies, which are becoming more and more software-intensive. Following that line of developments, based on our recent survey conducted in Finland in 2018, in this paper we explore the current state of the affairs with respect to how different organizations currently address agility and agile development in both IT and nonsoftware industrial sectors. The results show that operative goals (productivity, quality) are considered the most important ones to achieve by agile means. Scrum, Kanban and DevOps are the most frequently reported methods, and $\mathrm{SAFe}$ is the dominant scaling model. Lead time metrics are the most typically followed measurements. The operative goals as well as responsiveness are also the most highly ranked future aims. The impacts of digitalization are considered substantial but agile developments are seen to address them well. As a conclusion of this survey study, there is no "one agile way" for all. Different organizations seem to emphasize multiple aspects of agility when they develop, adapt and even transform themselves. Yet, also many commonalities were indicated.
\end{abstract}

Keywords: Agile software development, Enterprise agility, Transformation, Digitalization, Survey.

\section{Introduction}

Agile methods and practices are nowadays mainstream in software development organizations. Agile practices and ways of working are also increasingly applied in other functional areas and operations of large companies in different industry sectors. Moreover, modern software-intensive companies facing digitalization are transforming to become agile enterprises with business agility [1].

When agile software development methods and practices are extended and scaled up to enterprise levels, new competences and organizational capabilities beyond soft- 
ware engineering are required. It is thus important for each particular organization be able to understand their specific needs and agile means in order to achieve the goals of agility in their cases $[2,3]$.

There is a need for more empirical research to understand the current state of the agile practice in order to advance relevant software engineering research [4]. In this paper, we present current results about agility in mostly large organizations based on our recent survey study done in Finland. Various agile surveys have been conducted earlier, but current factors like disruptive digitalization may bring agile software development and business agility more topical for different organizations $[5,6,7]$. Compared to previous studies, we are interested not only in measuring how widely agile methods are currently applied in industrial practice but we want also to understand why and how different companies want to be(come) agile and how agility will possibly be evolving in the future in different software-intensive industries.

Previously, we have published selected results of the survey focusing on questions about Scaled Agile Framework (SAFe) adoption and agile transformation [8, 9]. This continuation paper examines primarily different questions of the survey data.

The rest of this paper is organized as follows. Section 2 charters the research background and Section 3 describes the survey design. In Section 4 designated results of the survey data are presented followed by comparative discussion in Section 5. In Section 6 we conclude with pointers to planned further work.

\section{Background}

\subsection{Current State of Practice and Trends}

Agile software development (ASD) has been practiced in industry - also in Finland for two decades now since the publication of the Agile Manifesto in the early 2000s. Since then agile development has evolved considerably [10].

One of the main development trends since the early days is that ASD has expanded from small colocated team setups to large-scale and distributed settings. Scaling frameworks - particularly Scaled Agile Framework (SAFe) - have been developed to assist in large-scale agile. However, many challenges are still faced [11, 12, 13].

Furthermore, agile has been expanded beyond software development to other business processes and organizational functions. Such agile transformations in organizations are conducted to achieve enterprise-level agility particularly in large, established companies [5,6]. Notably, agile adoptions are not just something that took place in the early era of ASD (2001-2010) but they are also currently ongoing in many organizations [14].

ASD methods and practices are nowadays applied also in hardware and systems engineering functions in product development organizations. That requires adapting the lightweight agile ways of working with the inherent constraints and requirements of complex systems development in the specific domains (e.g., automotive) $[15,16]$.

In all, since the early days 2000s both the technical and the business environments of software organizations and companies in different industry sectors and domains 
have changed considerably - sometimes even radically. Digitalization is nowadays a potential impact factor in many industry sectors, not limiting to the ICT sector alone.

Those are the underlying motivations for our empirical research. What agile software development has previously been may not reflect fully the actual state today and trends in the foreseeable future $[4,10]$.

\subsection{Research Streams}

In addition to the progressed state of the practice (Section 2.1), agile software development related research has advanced in many avenues both conceptually and empirically although it may have been lagging behind practice [4]. In general, agility is not specific to software development, and agile enterprises have been considered much before the Agile Manifesto in 2001 - particularly in manufacturing industries [17]. Some seminal works to ground and define information systems development (ISD) agility conceptually have been published [18]. Harmonized and consistent understanding of what constitutes agility in software systems development would make it possible to define comparable measures for rigorous empirical agile research $[19,20]$. However, even the agile terminology is still not fully settled and different terms are sometimes used interchangeably for the same concepts in research literature [13].

Current popular agile research themes include large-scale agile software development and organizational transformations for enterprise agile [4, 13, 21]. DevOps is one of the recent topics.

At the enterprise level recent research is advancing towards strategic agility and, ultimately, to agile software enterprises [7]. Like agile practice, agile research is gradually expanding beyond software to address strategic enterprise agility in software organizations and software-intensive companies. That research stream is our overarching and guiding motivation with the intention to contribute empirical evidence with this survey study. In essence, we are continuing here our agile research work started in early 2000s [2, 22].

Overall, we do recognize that our research themes are broad and partially multidisciplinary. In particular, there are additional foundational reference areas such as management and organization sciences addressing organizational transformations and digitalization in industries. It is not possible to cover such broad topics in here, but we consider them important for framing and comprehending agile development and agility in software-intensive company contexts with various contingencies [1].

\subsection{Prior and Related Studies}

Considering prior and related survey works, probably one of the most internationally known ones is the annual State of Agile survey by VersionOne Inc. [14]. It covers agile adoption, benefits of adopting agile, agile methods and practices used, success metrics of agile initiatives / agile transformations and agile projects, and scaling agile.

The European HELENA study initiated in 2016 has surveyed software systems development organizations for their agile development methods and practices with respect to their different combinations (hybrid approaches) in different industry do- 
mains [23]. It also explores the reasons for implementing hybrid development approaches and the ways they are formed in practice.

In Finland, a particular scientific survey study was done in 2012 [24]. It explored the usage of agile and lean methods, practices and principles, the goals for agile and lean adoptions, their challenges and limiting factors, and the perceived improvement effects of adoptions. Also the future plans were enquired. Furthermore, the Finnish Software Industry Survey examined agility in 2014 [25]. The results indicated differences in agility (e.g., flexibility) in different types and sizes of software organizations.

We have been experiencing industrial agile practice and changes in Finland during the period 2012-2018 (i.e., since the study in [24] and our survey). However, we are not aware of comparable longitudinal research about agile evolution in Finland.

\section{$3 \quad$ Research Design}

On the whole, the purpose of our survey research was to examine the current state of agile development and enterprise agility in Finland. We are interested in measuring how widely agile methods and practices are currently applied in industrial practice and how that is evolving. Moreover, we want to understand why different companies want to change - even transform - with agile means and how beneficial and successful their particular changes have been. Digitalization is one of our intriguing context factors. The target population was intentionally not limited to software companies since we were also interested in non-software companies (i.e., companies in other industries than IT) currently facing digitalization and becoming more softwareintensive as "software houses". We aimed to investigate not only the current whereabouts but also the future intentions of the companies.

The survey questionnaire was composed by starting from our selected main research themes of interests. The questionnaire structure comprised the following primary sections: Company's state of agile, Agile company transformation, Agile future of the company.

The specific questions were compiled on the one hand by referring to prior surveys for comparison purposes (e.g., $[24,26])$ and by deriving from our industrial experiences and our prior works (e.g., $[2,22])$ on the other hand. The draft questionnaire was first piloted both in our industrial and academic organizations. The final version consisted of total of 50 questions (including background information items). Certain questions were only applicable depending on their preceding selector questions (e.g., whether SAFe is in use or not). The questions were stated both in Finnish and in English. Table 1 presents the question items selected for analysis in this paper.

For data collection, the survey was implemented as a web-based online questionnaire with the Finnish / English language choice. We considered several potential distribution channels in order to reach a wide, representative sample population. However, due to pragmatic constraints we decided to use convenience sampling. The questionnaire was distributed with one Finnish consulting company mailing list mass postings to over 600 people collected from people interested in the company's offering of software consultancy and agile transformation services, and with social media. 
It was open for responding for 4 weeks in Nov-Dec 2018. We received 118 finished responses.

\section{$4 \quad$ Results}

Due to the space constraints, we cannot cover all the questions of our survey in here. In order to investigate the research themes of agility and agile development changes, in this paper we focus on the question items shown in Table 1.

Table 1. Questionnaire main sections and selected question items

Company's state of agile

- What agile methods and models are there in use in Your company?

- What particular (agile) measurements does the company follow up?

Agile company transformation

- Why does Your company want to become more agile?

- Where is the current overall focus of agility in Your company?

Agile future of the company

- What goals does the company attempt to achieve by agile means?

- How much does digitalization impact the agile development of Your company?

Background information (organization and respondent)

- What is the primary sector (line of business) of Your company?

- What is your primary role in Your organization?

\subsection{Background Information}

The majority $(75 \%)$ of our respondents in this sample were in large organizations: 44 reported that their organization is very large (more than 5000 persons) and also 44 large (more than 250 persons; In Finland companies with <250 employees are SMEs).

The respondents were also asked to designate the industry / business sector of their companies. The survey question listed 23 answering choices (denoted here as C1C23) and an open choice field. Our respondents represented more than 15 different domains with ICT sector being the most frequent one as shown in Table 2. However, notably, taking together the majority of the respondents reported their companies to be in other sectors than the ICT.

Table 2. What is the primary sector (line of business) of Your company?

\begin{tabular}{llll}
\hline (top 5) (multi choice not allowed) & $\begin{array}{l}\mathrm{n}(\mathrm{N}=115, \text { 'No answer' } \\
\text { choice N/A=0) }\end{array}$ & $\begin{array}{l}\% \\
\text { (out of N) }\end{array}$ \\
\hline C1 & ICT sector (including consulting), information & 38 & 33 \\
& technology & 27 & 23 \\
C2 & Financial sector (banking, insurance) & 13 & 11 \\
C4 & Telecom services &
\end{tabular}


\begin{tabular}{llll} 
C17 & Traffic, logistics & 8 & 7 \\
$\mathrm{C} 3$ & Retail sector & 4 & 3 \\
\hline
\end{tabular}

The questionnaire included also a few question items concerning the respondent's whereabouts and viewpoints of the company. Because our overall aim is to understand agility in software development organizations and companies as a whole, it is illuminating to have such contextual background information for analysis. Table 3 shows that our sample includes respondents with diverse roles. However, most of the respondents are directly involved with software development.

Table 3. What is your primary role in Your organization?

\begin{tabular}{lll}
\hline (top 10) (multi choice not allowed) & $\mathrm{n}(\mathrm{N}=117, \mathrm{~N} / \mathrm{A}=2)$ & $\%$ (out of N) \\
\hline $\begin{array}{l}\text { Software development or supporting it (including project } \\
\text { management) }\end{array}$ & 38 & 32 \\
Software process development, organizational develop- & 20 & 17 \\
ment (coach) & 11 & 9 \\
Architecture and technology development & 10 & 9 \\
Software development management (R\&D) & 8 & 7 \\
Product management & 6 & 5 \\
Business management & 4 & 3 \\
Business process development & 4 & 3 \\
Sales, marketing, customer relationships or equal & 3 & 3 \\
Information / Knowledge management & 2 & 2 \\
Personnel management (HR and supervising excluding & 2 & \\
top management) & & \\
\hline
\end{tabular}

\subsection{Company's State of Agile}

To begin with, one of the first questions of the questionnaire was about the agile methods and models usage in companies. The question presented 13 choices and an open field as shown in Table 4. Notably the choices included typical software methods (e.g., Scrum, XP) but also more organizational ones including scaling agile.

The majority of the respondents reported that Scrum, Kanban and DevOps are widely used. Also Lean methods appeared to be commonplace. Considering the agile scaling methods, Scaled Agile Framework (SAFe) was reported by more than half of our respondents while Large Scale Scrum (LeSS) and Disciplined Agile Delivery (DAD) are clearly less frequently used. In-house scaled agile models are not extremely unusual. We have earlier published more detailed results of the SAFe adoption elsewhere [9].

Table 4. What agile methods and models are there in use in Your company (multi choice)? (All methods and models which Your company uses in software development at least partially)

\begin{tabular}{lll}
\hline Choice & $\mathrm{n}(\mathrm{N}=116, \mathrm{~N} / \mathrm{A}=3)$ & $\%$ (out of $\mathrm{N})$ \\
\hline Scrum & 101 & 89
\end{tabular}




\begin{tabular}{lll} 
Kanban & 97 & 86 \\
DevOps & 73 & 65 \\
Scaled Agile Framework (SAFe) & 71 & 63 \\
Lean methods & 66 & 58 \\
Agile portfolio management & 20 & 18 \\
In-house scaled agile development model (what kind) & 16 & 14 \\
Agile rolling budgeting (or no budgeting at all) & 14 & 12 \\
Extreme Programming (XP) & 13 & 12 \\
Spotify model & 11 & 10 \\
Large Scale Scrum (LeSS) & 7 & 6 \\
Agile Modelling & 7 & 6 \\
Disciplined Agile Delivery (DAD) & 1 & 1 \\
Other & 1 & 1 \\
\hline
\end{tabular}

In addition to the agile method and model usage, we enquired also what particular measurements and metrics the companies use. The question was fully open with no prescribed choices given except 'No metrics'. Table 5 presents the different measurements that the respondents indicated. Note that some respondents reported many. Because of the open answering form, the responses (some of them were in Finnish) are here coded and grouped as qualitative data.

Development process operational measurements (lead time, cycle time; outcomes) appear to be the most typically followed internal attributes. However, also some external customer-related measurements (value, NPS) seem to be in place.

Table 5. What particular (agile) measurements does the company follow up?

\begin{tabular}{|c|c|c|}
\hline (open choice) & $\begin{array}{l}\mathrm{n}(\mathrm{N}=114, \\
\mathrm{N} / \mathrm{A}=22)\end{array}$ & $\begin{array}{l}\% \\
\text { (out of } \mathrm{N} \text { ) }\end{array}$ \\
\hline Key measurements (what): & 46 & 40 \\
\hline - $\quad$ lead time (features, epics, issues), cycle time, release cycle & 29 & \\
\hline - value & 9 & \\
\hline - $\quad$ defects & 6 & \\
\hline - $\quad$ outcomes, releases, deployments & 4 & \\
\hline - velocity & 4 & \\
\hline - $\quad$ automation (test, release) & 4 & \\
\hline - $\quad$ employee experience, "happy-or-not" & 4 & \\
\hline - $\quad$ predictability & 3 & \\
\hline - $\quad$ NPS, customer experience & 3 & \\
\hline - $\quad$ MISC. (several nominations, other than the ones above) & $<3$ & \\
\hline No metrics & 47 & 41 \\
\hline
\end{tabular}

\subsection{Agile Company Transformation}

In this survey, we were especially interested in discovering how extensively companies have performed agile adoptions and even company-wide agile transformations. 
The questionnaire included one specific question about when there has been executed or planned agile transformation in the company most recently and another question of how the company is / has been executing agile transformation. We have presented those results earlier elsewhere [8].

In this paper, we address the fundamental question for what reasons and purposes companies need and want to be or become more agile. Table 6 shows the responses for that question. There were 15 choices listed and an open choice field. Operative productivity and quality were reported most often, but overall there was a lot of variance in the reasons for agile adoption. That is, companies have many reasons for being or becoming (more) agile. We return to this in Sect. 4.4 (Table 10).

Table 6. Why does Your company want to become more agile (multi choice)?

\begin{tabular}{llcc}
\hline Choice & & $\mathrm{n}(\mathrm{N}=86$, & $\%$ \\
& $\mathrm{~N} / \mathrm{A}=2)$ & $($ out of N) \\
\hline 4$)$ & Productivity and quality (operative) & 62 & 72 \\
$3)$ & Responsiveness to customer/market changes (new features) & 56 & 65 \\
$8)$ & Job satisfaction & 46 & 53 \\
$12)$ & Fast/continuous organizational learning in rapidly changing & 44 & 51 \\
& operating environments & & 48 \\
$2)$ & Competitive and desirable products (new product develop- & 41 & 48 \\
& ment) & 41 & 44 \\
$9)$ & Project managebility & 38 & 44 \\
$6)$ & Customer experience & 38 & 43 \\
$11)$ & Strategic and organizational flexibility & 37 & 33 \\
$5)$ & Customer satisfaction & 28 & 31 \\
$1)$ & New business (product and service innovation) & 27 & 29 \\
$7)$ & User experience (UX) & 25 & 21 \\
$15)$ & Employer brand & 18 & 21 \\
$10)$ & Continuous budgeting, resourcing & 18 & 15 \\
$14)$ & Company image & 13 & 3 \\
$13)$ & Customers require / wish (agile development) & 3 & 3 \\
$16)$ & Other & & \\
\hline
\end{tabular}

Table 7. Why does Your company want to become more agile (multi choice)? - BY INDUSTRY SECTOR (see Table 2 and Table 6 for the choices)

\begin{tabular}{|c|c|c|c|c|c|c|}
\hline \multicolumn{2}{|c|}{ Industry sector } & \multicolumn{5}{|c|}{ Rank } \\
\hline & & $\# 1$ & $\# 2$ & \#3 & $\# 4$ & \#5 \\
\hline $\mathrm{C} 1$ & $\begin{array}{l}\text { ICT sector (including consulting), information } \\
\text { technology }\end{array}$ & 4) & 3) & 8) & 2) & $\begin{array}{l}9) \text {, } \\
12)\end{array}$ \\
\hline $\mathrm{C} 2$ & Financial sector (banking, insurance) & $\begin{array}{l}\text { 3), } \\
4), \\
8)\end{array}$ & & & 6) & 5) \\
\hline $\mathrm{C} 4$ & Telecom services & 4) & 3) & 9) & $\begin{array}{l}\text { 1), } \\
2), \\
5), \\
12)\end{array}$ & \\
\hline
\end{tabular}


Table 7 brings a comparative view of the relative importance of different reasons in different industry sectors (top 3, c.f., Table 2). The productivity and quality (choice 4) is ranked high in all the ICT $(\mathrm{C} 1)$, financial $(\mathrm{C} 2)$ and telecom service $(\mathrm{C} 4)$ sectors, followed by responsiveness (choice 3 ). There appears to be some emphasis on also customer-related reasons (choices 5,6) and employees (choice 8). Competitive and desirable products are also important reasons (choice 2). However, no statistical significance in those industry sectors can be conjectured here.

In addition to asking for the specific reasons for being or becoming agile, we inquired also more broadly, where the companies put currently weight on their agility in general. The question item listed 7 choices including 'No particular focusing' and an open choice field. Note that we did not give any prescribed definition of 'agility'. Table 8 shows that the respondents indicated operative goals most frequently. Both organizational and technological means are utilized.

Table 9 gives an industry-specific (top 3, c.f., Table 2) view of the agility emphasis. The ICT sector (C1) appears to put noticeable weight also on strategic goals while in the financial sector companies (C2) the overall agility of the company seems to be important. Again, no statistical significance in those sectors can be conjectured here.

Table 8. Where is the current overall focus of agility in Your company (multi choice)? (Evaluate the goals and means of the company from your point of view in your opinion)

\begin{tabular}{llcc}
\hline Choice & & $\mathrm{n}(\mathrm{N}=86$, & $\%$ (out of N) \\
& & $\mathrm{N} / \mathrm{A}=2)$ & \\
\hline 2$)$ & Operative goals (e.g., internal efficiency) & 44 & 51 \\
$4)$ & Organizational means (e.g., self-organizing teams) & 41 & 48 \\
$5)$ & Scaling agile development & 35 & 41 \\
$3)$ & Technological means (e.g., improved work methods) & 34 & 40 \\
$6)$ & Overall agility of the company & 27 & 31 \\
$1)$ & Strategic goals (e.g., speed advantage in the business sector) & 20 & 23 \\
$8)$ & No particular focusing & 4 & 5 \\
$7)$ & Other & 2 & 2 \\
\hline
\end{tabular}

Table 9. Where is the current overall focus of agility in Your company (multi choice)? - BY INDUSTRY SECTOR (see Table 2 and Table 8 for the choices)

\begin{tabular}{|c|c|c|c|c|c|c|}
\hline \multicolumn{2}{|c|}{ Industry sector } & \multicolumn{5}{|c|}{ Rank } \\
\hline & & $\# 1$ & \#2 & \#3 & $\# 4$ & \#5 \\
\hline $\mathrm{C} 1$ & $\begin{array}{l}\text { ICT sector (including consulting), information } \\
\text { technology }\end{array}$ & 2) & $\begin{array}{l}3) \text {, } \\
4)\end{array}$ & & 1) & 5) \\
\hline $\mathrm{C} 2$ & Financial sector (banking, insurance) & 6) & 2), & & $\begin{array}{l}\text { 3), } \\
5)\end{array}$ & \\
\hline $\mathrm{C} 4$ & Telecom services & 5) & 2) & 3) & 1) & 6) \\
\hline
\end{tabular}




\subsection{Agile Future of the Company}

In addition to probing the current state of agile and agility in companies, we are also interested in understanding their pictures of futures and the developmental scenario paths. For that, we asked the respondents to portray the time period 2018-2020 from their company's point of view.

Table 10 presents the responses of what the respondents see important that their companies attempt to achieve by agile means. The question item listed 13 different choices and an open choice. The basic agile goals of productivity, quality and responsiveness are the most indicated ones. However, there appear to be a wide range of other aims to attain covering both external customer-facing items (e.g., customer experience) and internal organizational ones (e.g., job satisfaction).

Table 10. What goals does the company attempt to achieve by agile means (multi choice)? (Appraise the 3 most important ones (weight, urgency))

\begin{tabular}{lll}
\hline Choice & $\mathrm{n}(\mathrm{N}=111$, & $\%$ \\
& $\mathrm{~N} / \mathrm{A}=4)$ & (out of N) \\
\hline Responsiveness to customer/market changes (new features) & 55 & 50 \\
Productivity and quality (operative) & 55 & 50 \\
Competitive and desirable products (new product development) & 28 & 25 \\
Customer experience & 27 & 24 \\
Job satisfaction & 27 & 24 \\
Project managebility & 26 & 23 \\
Fast/continuous organizational learning in rapidly changing operat- & 23 & 21 \\
ing environments & 21 & 19 \\
Customer satisfaction & 18 & 16 \\
Strategic and organizational flexibility & 12 & 11 \\
New business (product and service innovation) & 11 & 10 \\
User experience (UX) & 3 & 3 \\
Continuous budgeting, resourcing & 3 & 3 \\
Company image & 0 & 0 \\
Other & & \\
\hline
\end{tabular}

Finally, addressing directly the factor of digitalization, we asked the respondents to evaluate the impacts of digitalization and how effectively their agile development fit with them. The answering form was a 2-dimensional grid like depicted in Fig. 1. In addition, there was an open field for specifying particular factors of digitalization. Note that we did not give any prescribed definition of 'digitalization'.

The distribution in Fig. 1 shows that, overall, the respondents consider both the impacts of digitalization and the matching of agile developments in their companies substantial. For the particular digitalization impact factors AI, robotics (automation) and IoT were identified most frequently as presented in Table 11. Because of the open answering form, the responses (some of them were in Finnish) are here coded and grouped as qualitative data. 


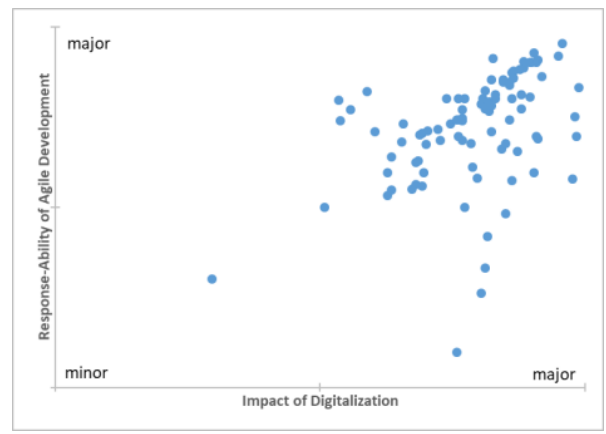

Fig. 1. How much does digitalization impact the agile development of Your company? (Net impact of the different factors and the corresponding usefulness of agile development) $-(\mathrm{N}=111, \mathrm{~N} / \mathrm{A}=20)$

Table 11. What factors of digitalization (e.g., artificial intelligence, IoT) affect in particular? $-(\mathrm{N}=58)$

\begin{tabular}{lll}
\hline (open comment) & $\mathrm{n}$ & $\begin{array}{l}\% \\
\text { (out of N) }\end{array}$ \\
\hline AI & 25 & 44 \\
automation, robotics, RPA & 20 & 34 \\
IoT, IIoT & 18 & 32 \\
data & 10 & 18 \\
VR, AR, XR & 5 & 9 \\
analytics & 4 & 7 \\
ML & 4 & 7 \\
5G & 4 & 7 \\
blockchain & 4 & 7 \\
MISC. (several nominations, other than the ones above) & $<4$ & \\
\hline
\end{tabular}

\section{Discussion}

\subsection{Comparative Analysis}

Goals. Overall, the respondents indicated a wide range of targets for their companies to pursuit by becoming more agile (see Table 6). Not surprisingly, operative goals (productivity, quality) were the most often reported ones but also customer-facing goals (responsiveness to customer/market changes and competitive, desirable products) were ranked high which aligns with the agile value of satisfying customers. Those ones are also emphasized as the future targets (Table 10). Notably also internal goals of job satisfaction and organizational learning were reported to be important ones (Table 6). However, overall there appear to be no profound differences in Table 6 and Table 10. This could be investigated further in different industry sectors (e.g., 
the choice Customer experience). One explanatory factor may also be how different respondents have interpreted the terms "more agile" and "agile means" and perceived the timeframe ("become", "future of the company") in these questions.

Comparing and contrasting with related prior research, Rodríguez et al. reported that the most important goals in agile and lean adoption are to increase productivity, improve product and service quality and to reduce development cycle times and timeto-market [24]. Those results are similar to our ones, operative productivity and quality being the top in Table 6. VersionOne found that the most important reasons for adopting agile are to accelerate software delivery, enhance ability to manage changing priorities and to increase productivity $[14,26]$. Those ones are also close to our results in Table 6.

Measurements and Metrics. Interestingly enough, a substantial share (41\%) of our respondents indicated that the company follows up no particular metrics (see Table 5). It could be due to the particular phases of the agile transformations in the companies with no specific metrics selected yet. It could possibly also depend on the formulation of the question - agile measurements and metrics could mean different things in different roles (Table 3) and company contexts. This is an area of a further study.

Comparing the current focus of agility in companies and the key metrics, there appear to be an alignment with operative goals being the main focus area (Table 8) and lead time metrics being the most frequently used measurements (Table 5). Furthermore, operative productivity and responsiveness were reported most often as the company agile targets (Table 6) which also aligns with the lead time and outcome metrics being the key ones in Table 5 .

In the prior related research, Rodríguez et al. does not cover any particular metrics [24]. However, their results include the perceived effects of adoption of agile and lean including for instance accelerated time-to-market/cycle time. We could expect those organizations to somehow measure that. In our results (Table 5) lead time, cycle time and velocity are related metrics.

VersionOne reports how success is measured with agile initiatives and with agile projects [26]. For the latter, customer/user satisfaction is indicated most. In our results, NPS and customer experience had only few occurrences.

Velocity and Effort estimates were found to be the most highly influential metrics reported in industrial agile studies included in one systematic literature review (SLR) [27]. In our results, velocity was not ranked high and effort estimates did not appear. The potential reason could be that these are rather team level metrics, and agile development has evolved to be a subject for the whole company. Lead time was the most often cited metric in our study while in contrast it was not ranked especially high in the abovementioned SLR.

Innovation. Facilitating innovation is one of the principal underlying goals of agile development methods, and empirical research evidence has been called for [19]. In our survey, the following question item choices address innovation in particular (see Table 1, Table 6, Table 7 and Table 10): 
- Why does Your company want to become more agile?

- What goals does the company attempt to achieve by agile means?

- New business (product and service innovation)

- Competitive and desirable products (new product development)

Interestingly, the goal 'Competitive and desirable products (new product development)' is ranked relatively high while the higher-level goal 'New business (product and service innovation)' appears to be less important (see Table 6 and Table 10).

Future of Agile. Agile software development has been practiced for the past two decades. During that time, there have been considerable evolution and expansion from small colocated teams to large-scale agile and agile enterprise transformations. Some of the most current and future trends foreseen are to join agile software development with new emerging technologies including AI, IoT, Big data and AR/VR [10]. Table 11 in our results indicate similar factors.

\subsection{Implications}

Managerial Implications. Following our findings and the analysis in Section 5.1, we suggest the following recommendations for practitioners of agile software production and for organizational agility development:

- Goals and means: Each organization should consider both the ends (agility) and the means (agile development) strategically and systemically in their specific business context. Each company should know why and how to change (Table 7).

- Measurements and metrics: The key measurements (Table 5) to follow should match with the agile goals to be attained (Table 10). The metrics should be defined unambiguously across the organization (e.g., "value" [28]).

- Innovation: Is there an overemphasis of (short-term) operative goals? Could fast/continuous organizational learning be leveraged more for competitive and desirable products (new product development) and new business (product and service innovation) - c.f., Table 10? Each company should realize not only operative agility but also enterprise (business) agility strategically and manage accordingly [1].

- Future of agile: Each company should continuously realize possible impacts of digitalization - which may be even disruptive - in its business domain(s) and industry sector (Table 11). The selected agile means should be fitting (Fig. 1).

Theoretical Implications. Our survey instrument can be elaborated with theoretical viewpoints of agility:

- Certain different questions (currently 50 items in the questionnaire) could be analyzed in combinations in order to form higher-level understanding of their potential relationships in different organizations. For instance, the goals (Table 6, Table 10) 
and measurements (Table 5) could conceptually be linked together. We had such an initial conceptual research model underlying the current questionnaire design.

- Considering the focus areas of agility (Table 8), the results could be viewed from different perspectives such project / process perspective vs. product perspective vs. organizational perspective. That could be used to profile agility in different organizations. We have earlier designed a provisional agility profiler instrument and now this survey questionnaire could possibly be coupled with that [2]. In addition, we have earlier proposed an agile transformation model, which could also be joined [3].

- In general, digitalization may bring both internal (e.g., automation) and external (e.g., user experience) impacts to different software-intensive organizations in different industry sectors. Understanding the whole in different companies needs holistic frames and models in order to be able to align the strategic ends and to assess how the selected agile means contribute in the specific contexts (c.f., Table 11).

\subsection{Threats to Validity and Limitations}

Considering the comparability and generalization, we acknowledge that a construct validity concern in our questionnaire is whether all the respondents have interpreted and conceived all the terms in the survey questionnaire in the same way (e.g., 'agile transformation'). However, also for instance Rodríguez et al. did not limit the usage of agile with specific definitions [24]. A similar exploratory strategy by not giving preset terminology definitions has been used also for instance in the HELENA survey [23]. We do not consider internal validity to be a significant concern since the purpose of the survey is primarily exploratory rather than explanatory. We have thus been cautious not draw decisive conclusions in this study. External validity is limited by the background information collected (see Section 4.1). Research comparisons with industrial surveys (e.g., VersionOne [14]) should take possible biases into account.

The design of our web-tool based questionnaire was such that the respondents could skip questions. This produced a considerable amount of partially filled responses - not every respondent replied to all questions. In this paper, our inclusion criteria has been to take into account only finished respondents.

Due to the company-specific call-out (Sect. 3), sampling bias is a threat. With the social media distribution, the response rate is unspecified. A general limitation is that we did not ask the respondents to identify their organizations. Consequently, we cannot tell the number of different responding companies. Rodríguez et al. acknowledged the same constraint [24]. Due to those restrictions we refrain from evaluating how representative our respondent sample is with respect to all Finnish industries and companies. However, the respondents represented several domains (see Table 2).

\section{Conclusions}

In this paper we have presented and analyzed selected results of the survey study, that we have recently (2018) conducted in Finland. We examined how different software 
organizations currently perform agile software development, how they consider organizational agility and how they change. Digitalization in different industry sectors was one of our interest factors. The research results indicate that usual operative goals (productivity, quality) and responsiveness are the most important targets to attain by agile means. However, companies pay attention also to higher-level organizational goals and transformational aims for their agility.

Our current survey data opens up room for further research. There are several questions (50 altogether in the questionnaire) which were not covered in this paper. They deserve further analysis. One potential approach could be to use the industry sector (Table 2) and company size as the context variables, and to calculate possible correlations. In addition, more cross-tabulations could be done (c.f., Table 7 and Table 9). One of our research hypotheses is that when the company management is committed and actively participating, the enterprise-level agile transformation becomes strategic and leads to determined, measured and sustainable effects (c.f., Table 8).

Furthermore, our future work plans include replicating the survey in other Nordic countries and annually in Finland. That would make it possible to conduct further comparative analysis and ascertain longer-term trends and evolutions - considering especially such factors as digital transformations in different industrial domains.

\section{References}

1. Kettunen, P., Laanti, M.: Future software organizations - agile goals and roles. Eur J Futures Res 5:16 (2017).

2. Kettunen, P.: Systematizing Software-Development Agility: Toward an Enterprise Capability Improvement Framework. Journal of Enterprise Transformation 2(2), 81-104 (2012).

3. Laanti, M.: Agile transformation model for large software development organizations. In: Tonelli, R. (eds.) Proceedings of the XP2017 Scientific Workshops, Article No. 19. ACM, New York, NY, USA (2017).

4. Mishra, A., Garbajosa, J., Wang, X., Bosch, J., Abrahamsson, P.: Future directions in Agile research: Alignment and divergence between research and practice. J Softw Evol Proc. 29, e1884 (2017).

5. Ronzon, T., Buck, J., Eckstein, J.: Making Companies Nimble - From Software Agility to Business Agility. IEEE Software 36(1), 79-85 (2019).

6. Prikladnicki, R., Lassenius, C., Carver, J.C.: Trends in Agile: Perspectives from the Practitioners. IEEE Software 33(6), 20-22 (2016).

7. Prikladnicki, R., Lassenius, C., Carver, J.C.: Trends in Agile: From Operational to Strategic Agility. IEEE Software 36(1), 95-97 (2019).

8. Kettunen, P., Laanti, M., Fagerholm, F., Mikkonen, T., Männistö, T.: Finnish Enterprise Agile Transformations: A Survey Study. In: Hoda, R. (eds.) Agile Processes in Software Engineering and Extreme Programming - Workshops. XP 2019. LNBIP, vol 364, pp. $97-$ 104. Springer, Cham (2019).

9. Laanti, M., Kettunen, P.: SAFe Adoptions in Finland: A Survey Research. In: Hoda, R. (eds.) Agile Processes in Software Engineering and Extreme Programming - Workshops. XP 2019. LNBIP, vol 364, pp. 81-87. Springer, Cham (2019).

10. Hoda, R., Salleh, N., Grundy, J.: The Rise and Evolution of Agile Software Development. IEEE Software 35(5), 58-63 (2018). 
11. Ebert, C., Paasivaara, M.: Scaling Agile. IEEE Software 34(6), 98-103 (2017).

12. Kalenda, M., Hyna, P., Rossi, B.: Scaling agile in large organizations: Practices, challenges, and success factors. J Softw Evol Proc. 30, e1954 (2018).

13. Dikert, K., Paasivaara, M., Lassenius, C.: Challenges and success factors for large-scale agile transformations: A systematic literature review. Journal of Systems and Software 119, 87-108 (2016).

14. Version One $13^{\text {th }}$ Annual State of Agile Report, https://stateofagile.versionone.com, last accessed 2019/5/21

15. Knauss, E.: The Missing Requirements Perspective in Large-Scale Agile System Development. IEEE Software 36(3), 9-13 (2019).

16. Prikladnicki, R., Lassenius, C., Carver, J.C.: Trends in Agile Updated: Perspectives from the Practitioners. IEEE Software 35(1), 109-111 (2018).

17. Goldman, S.L., Nagel, R.N., Preiss, K.: Agile competitors and virtual organizations: strategies for enriching the customer. Van Nostrand Reinhold, New York, NY, USA (1995).

18. Conboy, K.: Agility from First Principles: Reconstructing the Concept of Agility in Information Systems Development. Information Systems Research 20(3), 329-354 (2009).

19. Abrahamsson, P., Conboy, K., Wang, X.: 'Lots done, more to do': the current state of agile systems development research. European Journal of Information Systems 18, 281-284 (2009).

20. Dingsøyr, T., Dybå, T., Abrahamsson, P.: A Preliminary Roadmap for Empirical Research on Agile Software Development. In: Melnik, G., Kruchten, P., Poppendieck, M. (eds.) Proceedings of the Agile 2008 Conference, pp. 83-94. IEEE, Los Alamistos, CA, USA (2008).

21. Moe, N.B., Dingsøyr, T.: Emerging research themes and updated research agenda for large-scale agile development: a summary of the 5th international workshop at XP2017. In: Tonelli, R. (eds.) Proceedings of the XP2017 Scientific Workshops, Article No. 14. ACM, New York, NY, USA (2017).

22. Laanti, M., Salo, O., Abrahamsson, P.: Agile methods rapidly replacing traditional methods at Nokia: A survey of opinions on agile transformation. Information and Software Technology 53(3), 276-290 (2011).

23. Kuhrmann, M., et al.: Hybrid Software Development Approaches in Practice: A European Perspective. IEEE Software 36(4), 20-31 (2019).

24. Rodríguez, P., Markkula, J., Oivo, M., Turula, K.: Survey on Agile and Lean Usage in Finnish Software Industry. In: Runeson, P., Höst, M., Mendes, E., Andrews, A., Harrison, R. (eds.) ESEM '12 ACM-IEEE International Symposium on Empirical Software Engineering and Measurement, pp. 139-148. ACM, New York, NY, USA (2012).

25. Finnish Software Industry Survey, http://www.softwareindustrysurvey.fi/focus-onflexibility-agility-in-software-development/, last accessed 2019/3/10

26. Version One $12^{\text {th }}$ Annual State of Agile Report, https://stateofagile.versionone.com, last accessed 2019/3/10

27. Kupiainen, E., Mäntylä, M.V., Itkonen, J.: Using metrics in Agile and Lean Software Development - A systematic literature review of industrial studies. Information and Software Technology 62, 143-163 (2015).

28. Alahyari, H., Berntsson Svensson, R., Gorschek, T.: A study of value in agile software development organizations. Journal of Systems and Software 125, 271-288 (2017). 